\title{
TRANSAKSI E-COMMERSE DALAM EKONOMI SYARIAH
}

\author{
Mahmudah Mulia Muhammad \\ Universitas Islam Negeri Alauddin Makassar \\ Udha009@gmail.com
}

\begin{abstract}
The advancement of telecommunications, information and computer technology has led to changes in culture and the demands of everyday life, so that it has given birth to new patterns of relationships, including in the business world. One of its flagship media is through e-commerce (electronic commerce). The emergence of concerns about e-commerce transactions, especially the Islamic community in Indonesia, both from a security perspective and a sharia perspective. This paper aims to analyze e-commerce transactions in Islamic economics. The results of the analysis concluded that technically the transaction, both in the form of buying and selling services or goods, if the goods are delivered in a formidable form of non-digital, then e-commerce transactions can be analogous to the sale of al-salam, which has been prescribed from the beginningthe beginning of Islam through the Sunnah of the Holy Prophet. The use of ecommerce in Indonesia is permitted while the two parties understand each other. This article is also to provide general guidance about e-commerce users in running their business.
\end{abstract}

Keywords: Bai 'as-salam, E-Commerce, Islamic Economics.

\begin{abstract}
Abstrak
Kemajuan teknologi telekomunikasi, informasi dan komputer, telah menyebabkan terjadinya perubahan kultur dan tuntutan hidup sehari-hari, sehingga telah melahirkan pola hubungan baru, di antaranya dalam dunia bisnis. Salah satu media andalannya adalah melalui e-commerce (electronic commerce). Munculnya kekhawatiran terhadap transaksi e-commerce khususnya masyarakat Islam di Indonesia, baik dari prespektif keamanan dan prespektif syariah. Tulisan ini bertujuan untuk menganalisis transaksi e-commerce dalam ekonomi syariah. Hasil analisis disimpulkan bahwa secara teknis transaksinya, baik dalam bentuk jual-beli jasa atau barang, kalau barang tersebut diserahkan secara tangguh karena berbentuk non digital, maka transaksi e-commerce dapat dianalogikan kepada jual-beli al-salam, yang telah disyariatkan semenjak awal mulanya Islam melalui Sunnah Nabi saw. Penggunaan e-commerce di Indonesia dibolehkan selagi antara kedua belah pihak saling paham. Artikel ini juga untuk memberikan panduan umum tentang pengguna e-commerce dalam menjalankan bisnisnya.
\end{abstract}

Kata Kunci : Bai’ as-salam, E-Commerce, Ekonomi Syariah. 


\section{PENDAHULUAN}

Pada era globalisasi saat ini, penguasaan teknologi menjadi prestise dan indikator kemajuan suatu negara. Negara dikatakan maju jika memiliki tingkat penguasaan teknologi tinggi (high technology), sedangkan negara-negara yang tidak bisa beradaptasi dengan kemajuan teknologi sering disebut sebagai negara gagal (failed country). ${ }^{1}$

Kemajuan IT secara tidak langsung merubah pola fikir seseorang, khususnya masyarakat Islam dalam penggunaan media online. ${ }^{2}$ Layanan online ini memacu cara baru dalam menjalankan aktifitas sehari-hari, kehidupan seperti ini dikenal dengan e-life, artinya kebutuhan di dunia ini sudah di pengaruhi oleh kebutuhan secara elektronik, dan dewasa ini sudah ramai dengan berbagai huruf yang di awali dengan "e", seperti e-commerce, e-library, e-goverment, e-medicine, ebiodiversity, e-laboratory, dan masih banyak lagi yang berjenis elektronika. ${ }^{3}$

Dampak perkembangan teknologi merambah hingga ke Indonesia. Hal ini ditandai dengan semakin menjamurnya bisnis e-commerce. E-commerce telah merevolusi perilaku penjual dan konsumen dalam bertransaksi, dimulai dari menawarkan barang, memasarkan hingga bertransaksi. Semua dilakukan tanpa batas waktu dan jarak dan dilakukan tanpa perlu bertatap muka secara langsung. Apalagi saat ini website e-commerce telah banyak ditawarkan, tidak hanya website berbayar melainkan banyak pula yang nonpremium (gratis) sehingga menjadi tidak ada alasan bagi pelaku usaha untuk tidak turut serta dalam berbisnis melalui media $e$-commerce. ${ }^{4}$

Sesuai perkembangan zaman berkat kemajuan ilmu pengetahuan dan teknologi modern, banyak bermunculan bentuk-bentuk transaksi yang belum ditemui pembahasannya di dalam fikih klasik. Banyak sekali usaha-usaha manusia yang berhubungan dengan barang danjasa. Di dalam transaksi saja para ulama menyebutkan tidak kurang dari 25 macam, antara lain: jual-beli inah (transaksi yang pembayarannya di belakang), jual-beli urban (jual-beli dengan pengikat uang muka), jual-beli ahlul-hadhar (orang kota) dengan al-badi (orang desa), khiyar, jual-beli ushur dan tsamar (buah-buahan), salam (pesanan), istishna (pemesanan

\footnotetext{
${ }^{1}$ Muhamad Ngafifi, Kemajuan Teknologi dan Pola Hidup Manusia dalam Perspektif Sosial Budaya, Jurnal Pembangunan Pendidikan Fondasi dan Aplikasi, Volume 2 Nomor 1 2014, h. 34.

${ }^{2}$ Muhammad Nizar, Pendekatan Komprehensif E-Commerce Prespektif Syariah, Jurnal Perisai, Vol 2 No.1 April 2018, h. 75-76.

${ }^{3}$ Erhans Anggawirya, Internet Sekarang Belajar Sekarang Lancar, (Jakarta: Ercontara Rajawali, 2003). h. 10.

${ }^{4}$ Naili Saadah, Perencanaan Keuangan Islam Sederhana dalam Bisnis E-Commerce pada Pengguna Online Shop, Economica: Jurnal Ekonomi Islam, Volume 9 Nomor 1 2018, h. 112. 
membuat barang), rahn (gadai), kafalah (jaminan), wakalah (perwakilan), syirkah (perserikatan), ijarah (sewa-menyewa), wadi'ah (barang titipan) dan lain-lain. ${ }^{5}$

Islam sebagai agama universal yang tidak lekang oleh zaman untuk mengatur akidah, syariah dan akhlak secara komprehensif, hadir menjadi pedoman bagi setiap muslim untuk melakukan kegiatan transaksi bisnis e-commerce. Karena salah satu aspek penting terkait hubungan antar manusia adalah ekonomi. ${ }^{6}$

Ekonomi menjadi dasar untuk mencukupi kebutuhan dan kesejahteraan seseorang. Jika dalam ekonomi konvensional kesejahteraan diartikan sebagai tercukupinya kebutuhan untuk mencapai kepuasan pribadi maka ekonomi Islam memandang kesejahteraan dengan perspektif yang lebih luas. Kesejahteraan sosial dalam ekonomi Islam berawal dari konsep pemikiran sosio ekonomi yang digagas oleh Al-Ghazali. Imam Al-Ghazali dalam bukunya, Ihyā 'Ulūm al-Dīn, mengungkapkan bahwa kesejahteraan masyarakat akan terwujud ketika terpenuhinya lima tujuan dasar manusia, yakni agama, jiwa, akal, harta dan keturunan.

Berangkat dari latar belakang tersebut maka penulis tertarik untuk menganalisis lebih lanjut tentang transaksi e-commerce dalam ekonomi syariah.

\section{METODE PENELITIAN}

Penelitian ini dilakukan berdasarkan studi pustaka dengan berbagai referensi jurnal dan buku serta beberapa artikel terbaik dan terupdate. Penelitian Pustaka (library research) yaitu Penelitian dilaksanakan dengan mengumpulkan data dan landasan teoritis dengan mempelajari buku, karya ilmiah, hasil penelitian terdahulu, jurnal-jurnal terkait, artikel-artikel yang terkait serta sumber-sumber yang terkait dengan penelitian sesuai dengan penelitian yang diteliti. Setelah semua data telah diperoleh berhasil dikumpulkan selama proses penelitian baik data primer dan data sekunder dianalisis secara kualitatif kemudian disajikan secara deskriptif yaitu menjelaskan, menguraikan, menggambarakan permasalahan yang berkaitan dengan transaksi e-commerse dalam ekonomi syariah.

\footnotetext{
${ }^{5}$ Deka Meuthia Novari, Penerapan Sistem Reseller Perspektif Hukum Ekonomi Syariah (Studi Kasus Usaha Online Shop di Pertokoan Barokah Galeri Bukit Kemuning, Al-Mizan, Volume 01 Nomor 01 September 2019, h. 40-41.

${ }^{6}$ Arwani, Agus. Epistemologi Hukum Ekonomi Islam (Muamalah), Religia: Jurnal Ilmu-Ilmu Keislaman, Volume 15 No. 1 2012, h. 125.

78
} 


\section{PEMBAHASAN}

\section{A. E-commerce dalam Ekonomi Syariah}

E-Commerce adalah suatu proses membeli dan menjual produk-produk secara elektronik oleh konsumen dan dari perusahaan ke perusahaan dengan komputer sebagai perantara transaksi bisnis. Media yang dapat digunakan dalam aktivitas $e$ commerce adalah world wide web internet. ${ }^{7}$ E-Commerce adala pembelian, penjualan dan pemasaran barang serta jasa melalui sistem elektronik. Seperti radio, televisi dan jaringan komputer atau internet. ${ }^{8}$

E-Commerce adalah penggunaan jaringan komunikasi dan komputer untuk melaksanakan proses bisnis. Pandangan populer dari e-commerce adalah penggunaan internet dan komputer dengan browser Web untuk membeli dan menjual produk. ${ }^{9}$ E-commerce atau kependekan dari electronic commerce (perdagangan secara electronik), merupakan transaksi bisnis yang terjadi dalam jaringan elektronik, seperti internet. Siapapun yang dapat mengakses komputer, memiliki sambungan ke internet, dan memiliki cara untuk membayar barangbarang atau jasa yang mereka beli, dapat berpartisipasi dalam e-commerce. ${ }^{10}$

Sesui dengan definisi beberapa ahli di atas, disimpulkan pengertian $e$ commerce adalah proses transaksi jual beli yang dilakukan melalui internet dimana website digunakan sebagai wadah untuk melakukan proses tersebut.

E-commerce dapat dibagi menjadi beberapa jenis yang memiliki karakteristik berbeda-beda. Penggolongan e-commerce dibedakan sebagai berikut: 1). Business to Consumer (B2C), 2). Business to business (B2B). 3). Consumer to Consumer (C2C). 4). Peer-to-peer (P2P). 5). Mobile Commerce (M-Commerce).$^{11}$

E-commerce yang dimaksud dalam tulisan ini termasuk dalam golongan Business to Consumer (B2C), yang mencakup transaksi jual, beli, dan pemasaran kepada individu pembeli dengan media internet melalui penyedia layanan $e$ commerce, seperti Shoope, Lazada, dan JD.ID. Di dalam proses transaksi $e$ commerce, baik itu B2B maupun B2C, melibatkan lembaga perbankan sebagai institusi yang menangani transfer pembayaran transaksi.

\footnotetext{
${ }^{7}$ Shabur Miftah Maulana Heru Susilo dan Riyadi, Implementasi E-Commerce sebagai Media Penjualan Online (Studi Kasus Pada Toko Pastbrik Kota Malang), Jurnal Administrasi Bisnis, Vol. 29 No. 1 Desember 2015, h. 3.

8Jony Wong, Internet Marketing for Beginners, (Jakarta: Elex Media Komputindo, 2010). h. 33.

${ }^{9}$ Ambo Aco dan Andi Hutami Endang, Analisis Bisnis E-Commerce pada Mahasiswa Universitas Islam Negeri Alauddin Makassar, Jurnal Insypro, Vol. 2, No. 1 2017, h. 3.

${ }^{10}$ Shelly Cashman Varmaat, Discovering Computers: Menjelajah Dunia Komputer Fundamental. Edisi 3 (Jakarta: Salemba Infotek, 2007). h. 83.

${ }^{11}$ Dewi Irmawati, Pemanfaatan E-Commerce dalam Dunia Bisnis, Jurnal IImiah Orasi Bisnis, Edisi Ke-VI November 2011, h. 99.
} 
Sebuah perusahaan e-commerce bisa bertahan tidak hanya mengandalkan kekuatan produk saja, tapi dengan adanya tim manajemen yang handal, pengiriman yang tepat waktu, pelayanan yang bagus, struktur organisasi bisnis yang baik, jaringan infrastruktur dan keamanan, desain situs web yang bagus, beberapa faktor yang termasuk: 1). Menyediakan harga kompetitif 2). Menyediakan jasa pembelian yang tanggap, cepat, dan ramah. 3). Menyediakan informasi barang dan jasa yang lengkap dan jelas. 4). Menyediakan banyak bonus seperti kupon, penawaran istimewa, dan diskon. 5). Memberikan perhatian khusus seperti usulan pembelian. 6). Menyediakan rasa komunitas untuk berdiskusi, masukan dari pelanggan, dan lain-lain. 7). Mempermudah kegiatan perdagangan.

E-commerce memberikan manfaat antara lain: 1) Mendapatkan pelanggan baru. 2) Menarik konsumen untuk tetap bertahan. 3) Meningkatkan mutu layanan. Dengan adanya e-commerce memungkinkan perusahaan dapat meningkatkan layanan dengan melakukan interaksi yang lebih personal sehingga dapat memberikan informasinya sesuai dengan apa yang diinginkan oleh konsumen. 4) Melayani konsumen tanpa batas waktu.

E-commerce memberikan pilihan kepada produsen tentang jenis usaha dan skala usaha yang akan dikembangkan. Dengan mengimplementasikan teknologi informasi e-commerce, produsen dapat memilih untuk mengembangkan target pasar kepada pasar global atau hanya fokus terhadap segmen pasar tertentu. ${ }^{12}$ Dengan menggunakan e-commerce, produsen dapat merubah daftar harga atau melakukan kustomisasi produk atau jasa yang ditawarkan dan terinformasikan secara cepat melalui website. Sesuatu yang biasanya memerlukan waktu yang lama untuk dilaksanakan atau diintegrasikan, dengan e-commerce menjadi lebih cepat.

Suatu konsep jual-beli dalam fikih muamalah yang sangat sepadan dengan konsep e-commerce ini adalah jual-beli al-salam, kalau barangnya berbentuk pesanan yakni yang non digital, dan jual beli umum (buyu') untuk jenis-jenis barang yang digital. Untuk jenis jual beli yang terakhir ini, tidak akan dijelaskan lebih jauh, karena telah dapat dipahami bagaikan jual-beli yang lazim dilakukan oleh banyak orang selama ini.

Jual-beli al-salam dapat ditemukan dalilnya dalam sabda Rasulullah saw, sebagaimana diriwayatkan oleh Bukhari dan Muslim dari Ibn Abbas:

\footnotetext{
${ }^{12}$ Mohd Rizal Palil, The Effect Of E-Commerce On Malaysian Tax System: An Empirical Evidence From Academicians And Malaysian Tax Practitioners, Jurnal Akuntansi \& Keuangan, Vol. 6, No. 1, Mei 2011, h. 9.
}

80 


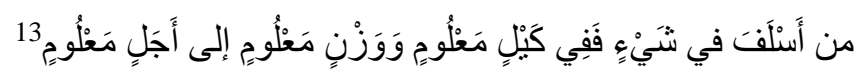

Artinya:

Siapa yang melakukan jual-beli salam, hendaklah melakukannya dengan takaran dan timbangan yang jelas, sampai batas waktu tertentu.

Berdasarkan hadis tersebut di atas, maka para ulama sepakat akan kebolehan jual beli al-salam ini, sejauh sesuai dengan garisan Rasulullah saw tersebut. Kendati objek transaksi salam dimaksudkan dalam hadis adalah masalah pertanian sesuai dengan kondisi yang ada pada waktu, saat ini tentunya tidak cukup hanya sebatas masalah pertanian saja. Artinya akan dapat dikembangkan dalam aspek dan bentuk objek transaksi lainnya.

Dengan adanya penjelasan ten- tang jual beli al-salam di atas, dapat diambil kesimpulan bahwa secara prinsip bentuk transaksi jual beli antara al-salam dengan e-commerce adalah sama, yakni sama-sama berbentuk pesanan yang penyerahan barangnya ditangguhkan,sedangkan pembayarannya sama-sama tunai. Kendati pada al-salam pembayarannya secara konvensional, yakni langsung berbentuk uang tunai, sesuai dengan kondisi peradaban yang ada pada waktu itu, sedangkan "tunai" dalam sistem pembayaran pada e-commerce dengan memakai media e-mail dan credit card (kartu kredit) secara on line.

Secara garis besar, antara e-commerce dengan bai' as-salam memiliki persamaan dan perbedaan yang sangat mendasar. Berdasarkan uraian di atas, paling tidak ada beberapa hal yang peneliti dapat rumuskan terkait dengan hal tersebut; Baik bai' as-salam maupun e-commerce sama-sama merupakan aktivitas jual beli. Maka seperti halnya transaksi jual beli, disyaratkan paling tidak ada 4 hal yang harus terpenuhi; yaitu pembeli, penjual, alat tukar (uang), dan barang yang diperjual-belikan atau obyek transaksi.

Hanya saja, pada transaksi $e$-commerce maupun bai' as-salam obyek transaksi ditangguhkan penyerahannya walaupun telah terjadi kesepakatan jual beli antara penjual dan pembeli. Setidaknya ini lah persamaan mendasar antara e-commerce dan bai' as-salam. Adapun beberapa perbedaan spesifik ditemukan juga dalam di antara kedua konsep tersebut, khusunya dalam hal model penawaran, pembayaran, serta pengiriman dan penerimaan. Perbedaan ini tidak secara otomatis menyatakan bahwa e-commerce tidak sah. Kecuali nyata pertentangannya dengan prinsip dan nilai ajaran Islam di bidang muamalah, yaitu mengandung unsur maisir (judi), gharar (penipuan), riba dan produk atau jasa yang ditawarkan adalah termasuk yang diharamkan oleh ajaran Islam.

${ }^{13} \mathrm{Al}-K a h l a n y$, Subul al-Salam, Jilid 4, (Bandung: Dahlan, t.th.). h. 49. 


\section{B. Analisis Penerapan E-Commerce dalam Ekonomi Syariah}

Perdagangan merupakan salah satu bagian dari Islam, bahkan Rasulullah saw merupakan seorang pedagang sukses, untuk melakukan aktifitas perdagangan mereka sampai ke negara yang jauh dari tanah air mereka, yaitu negara Syam dan Syiria. ${ }^{14}$ Tidak hanya bisnis saja yang sampai ke berbagai negara, ternyata penyebaran Islam ke berbagai belahan duniapun juga melalui aktivitas bisnis. ${ }^{15}$.

Prinsip Islam dalam berbisnis berdasarkan pada kebebasan, dalam aktivitas ekonomi manusia bebas dalam mengimplementasikan kaidah-kaidah Islam, karena masalah ekonomi masuk dalam aspek muamalah, bukan ibadah. ${ }^{16}$ Maka berlaku padanya kaidah umum,

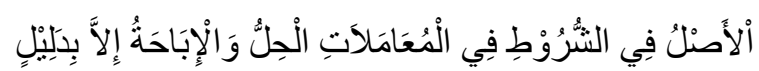

(hukum asal menetapkan syarat dalam muamalah adalah halal dan diperbolehkan kecuali ada dalil (yang melarangnya). Yang tidak boleh dilakukan Islam ialah riba dan ketidakadilan. Dalam aspek ini kebebasan manusia sesungguhnya tidak mutlak, tetapi kebebasan yang berkeadilan dan bertanggung jawab. $^{17}$

Landasan normatif etika bisnis ekonomi syariah bersumber dari al-Quran dan Hadis. Dalam konteks ini dapat dibagi menjadi empat kelompok: 1) landasan tauhid, 2) landasan keseimbangan, 3) landasan kehendak bebas, dan 4) landasan pertanggungjawaban. ${ }^{18}$ Bisnis dalam ekonomi syariah bertujuan untuk mencapai empat kelompok: 1) target hasil: profit-materi dan benefit-nonmateri, 2) pertumbuhan, 3) keberlangsungan, dan 4) keberkahan. ${ }^{19}$

Al-Quran tidak hanya menjelaskan terkait perilaku, perkawinan dan perceraian, kebersihan, tetapi juga menjelaskan aturan terperinci tentang perdagangan, bunga, hutang, kontrak, wasiat, politik, serta industri keuangan. Islam telah mengizinkan dan mendorong aktivitas bisnis, Islam juga memaparkan prinsip-prinsip dasar perilaku ekonomi sebagai konsumen, produsen, dan pemilik kekayaan.

Islam memperbolehkan transaksi jual-beli yang dilakukan sesuai dengan syariat Islam maupun sesuai dengan ekonomi syariah. Prinsip umum ekonomi

\footnotetext{
${ }^{14}$ P3EI, Ekonomi Islam (Jakarta: Rajawali Press, 2011). h. 97.

${ }^{15}$ Mohamad Hidayat, The Sharia Economic, Pengantar Ekonomi Syariah, (Jakarta: Zikrul Hakim, 2010). h. 51.

${ }^{16}$ Rachmat Syafe'i, Fiqih Muamalah, (Bandung: Pustaka Setia, 2001). h. 13.

${ }^{17}$ Hendi Suhendi, Fiqih Muamalah: Membahas Ekonomi Islam (Jakarta: Raja Grafindo Persada, 2002). h. 41.

${ }^{18}$ Muslich, Etika Bisnis Islami, (Yogyakarta: Ekonisia Fakultas Ekonomi UII, 2010), h. 27.

${ }^{19}$ Muhammad Ismail Yusanto dan Muhammad Karebet Widjajakusuma, Menggagas Bisnis Islami, (Jakarta: Gema Insani Press, 2002), h. 18.
} 
syariah ialah karakter bisnis yang sangat menentukan sukses tidaknya sebuah bisnis yang mana harus dimiliki pebisnis apalagi pebisnis muslim atau muslimat yang menghendaki kesusksesan dalam berbisnis. Sesuai dengan teori di dalam prinsip ekonomi syariah yaitu: Prinsip kejujuran (al-shidq) adalah sifat (keadaan) jujur, ketulusan (hati), kelurusan (hati). Prinsip Keadilan (al-'adhilah) adalah suatu masalah yang sangat sulit diterapkan, mudah dikatakan tetapi sulit dilakukan. Konsep keadilan ekonomi dalam Islam mengharuskan setiap orang mendapatkan haknya dan tidak mengambil hak atau bagian orang lain. Prinsip Tanggung jawab merupakan suatu prinsip dinamis yang berhubungan dengan prilaku manusia.

Beraktivitas didunia kerja dan bisnis, Islam mewajibkan berbuat adil, tidak terkecuali pada pihak yang tidak disukai. Hal ini sesuai dengan firman Allah swt dalam QS Al-Maidah/5: 8,

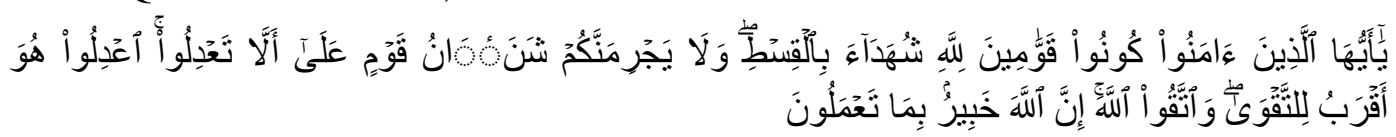

Terjemahnya:

Hai orang-orang yang beriman hendaklah kamu jadi orang-orang yang selalu menegakkan (kebenaran) karena Allah, menjadi saksi dengan adil. Dan janganlah sekalikali kebencianmu terhadap sesuatu kaum, mendorong kamu untuk berlaku tidak adil. Berlaku adillah, karena adil itu lebih dekat kepada takwa. Dan bertakwalah kepada Allah, sesungguhnya Allah Maha Mengetahui apa yang kamu kerjakan. ${ }^{20}$

Berdasarkan ayat tersebut di atas memberikan pengertian bahwa bentuk transaksi penerapan e-commerce termasuk sistem usaha yang sah, dan terdapat unsur ketidakadilan di dalam transaksi sesuai prinsip ekonomi syariah. Ekonomi Syariah memberikan ketentuan bahwa pelaku bisnis harus mengetahui, memahami dan juga menjalankan prinsip-prinsip ekonomi syariah, seperti kejujuran, keadilan dan bertanggungjawab agar semua aktivitas bisnis berjalan dengan baik dan mendapatkan keberkahan dari Allah swt.

\section{PENUTUP}

\section{A. Kesimpulan}

Berdasarkan pembahasan diatas maka, disimpulkan sebagai berikut :

1) Dilihat dari sisi teknis transaksinya, baik dalam bentuk jual-beli jasa atau barang, kalau barang tersebut diserahkan secara tangguh karena berbentuk non digital, maka transaksi e-commerce dapat dianalogikan kepada jual-beli

\footnotetext{
${ }^{20}$ Kementerian Agama RI, Al-Quran dan Terjemahnya, (Solo: Sigma, 2010). h. 47.
} 
al-salam, yang telah disyariatkan semenjak awal-awal Islam melalui Sunnah Nabi saw. Berbeda halnya kalau objek barang yang ditransasksikan itu berbentuk digital yang dapat langsung diterima oleh pembali setelah pembayaran dilakukan, maka jenis jual-beli ini terkategori kepada jual beli umum/biasa, yang diistilahkan dalam kitab fikih dengan buyu'.

2) Paparan artikel di atas, sudah menjawab terkait kekhawatiran umat muslim tentang hukum yang berkaitan dengan bisnis e-commerce, yang rumornya terdapat gharar, riba dan isu-isu yang terkait ekonomi syariah terutama di Indonesia. Penggunaan e-commerce di Indonesia dibolehkan selagi antara kedua belah pihak saling paham. Artikel ini juga untuk memberikan panduan umum tentang pengguna $e$-commerce dalam menjalankan bisnisnya. 


\section{DAFTAR PUSTAKA}

Aco, Ambo dan Andi Hutami Endang. Analisis Bisnis E-Commerce pada Mahasiswa Universitas Islam Negeri Alauddin Makassar. Jurnal Insypro, Volume 2 Nomor 12017.

Al-Kahlany. Subul al-Salam, Jilid 4. Bandung: Dahlan, t.th.

Anggawirya, Erhans. Internet Sekarang Belajar Sekarang Lancar. Jakarta: Ercontara Rajawali, 2003.

Arwani, Agus. Epistemologi Hukum Ekonomi Islam (Muamalah). Religia: Jurnal Ilmu-Ilmu Keislaman, Volume 15 Nomor 12012.

Hidayat, Mohamad. The Sharia Economic, Pengantar Ekonomi Syariah. Jakarta: Zikrul Hakim, 2010.

Irmawati, Dewi. Pemanfaatan E-Commerce dalam Dunia Bisnis. Jurnal Ilmiah Orasi Bisnis, Edisi Ke-VI November 2011.

Kementerian Agama RI. Al-Quran dan Terjemahnya. Solo: Sigma, 2010.

Maulana, Shabur Miftah, Heru Susilo dan Riyadi. Implementasi E-Commerce sebagai Media Penjualan Online (Studi Kasus Pada Toko Pastbrik Kota Malang). Jurnal Administrasi Bisnis, Vol. 29 No. 1 Desember 2015.

Muslich. Etika Bisnis Islami. Yogyakarta: Ekonisia Fakultas EkonomiUII, 2010.

Ngafifi, Muhamad. Kemajuan Teknologi dan Pola Hidup Manusia dalam Perspektif Sosial Budaya. Jurnal Pembangunan Pendidikan: Fondasi dan Aplikasi, Volume 2 Nomor 12014.

Nizar, Muhammad. Pendekatan Komprehensif E-Commerce Prespektif Syariah. Jurnal Perisai. Volume 2 Nomor 1 April 2018.

Novari, Deka Meuthia. Penerapan Sistem Reseller Perspektif Hukum Ekonomi Syariah (Studi Kasus Usaha Online Shop di Pertokoan Barokah Galeri Bukit Kemuning). Jurnal Al-Mizan, Volume 01 Nomor 01 September 2019.

P3EI. Ekonomi Islam. Jakarta: Rajawali Press, 2011.

Palil, Mohd Rizal. The Effect Of E-Commerce On Malaysian Tax System: An Empirical Evidence From Academicians And Malaysian Tax Practitioners. Jurnal Akuntansi \& Keuangan, Volume 6 Nomor 1 Mei 2011. 
Saadah, Naili. Perencanaan Keuangan Islam Sederhana dalam Bisnis ECommerce pada Pengguna Online Shop. Economica: Jurnal Ekonomi Islam, Volume 9 Nomor 12018.

Suhendi, Hendi. Fiqih Muamalah: Membahas Ekonomi Islam. Jakarta: Raja Grafindo Persada, 2002.

Syafe'i, Rachmat. Fiqih Muamalah. Bandung: Pustaka Setia, 2001.

Varmaat, Shelly Cashman. Discovering Computers: Menjelajah Dunia Komputer Fundamental. Edisi 3. Jakarta: Salemba Infotek, 2007.

Wong, Jony. Internet Marketing for Beginners. Jakarta: Elex Media Komputindo, 2010.

Yusanto, Muhammad Ismail dan Muhammad Karebet Widjajakusuma. Menggagas Bisnis Islami. Jakarta: Gema Insani Press, 2002. 